Thorax (1965), 20, 393.

\title{
Carcinoid syndrome and oat-cell carcinoma of the bronchus
}

\author{
J. G. AZZOPARD I ANDA.R. BELLAU \\ From the Department of Morbid Anatomy, Postgraduate Medical School of London, and the Department \\ of Medicine, Edgware General Hospital
}

In 1960 Williams and Azzopardi reported the first case of oat-cell carcinoma of the bronchus associated with the carcinoid syndrome and active production of 5-hydroxyindoles. No similar case has to our knowledge been recorded until recently when Gowenlock, Platt, Campbell, and Wormsley (1964) reported a patient with an oat-cell carcinoma of the bronchus; this secreted 5-hydroxytryptophan (5-HTP) in contrast to the conventional 5-hydroxytryptamine (5-HT) secreting carcinoid tumour. Though assay of the tumour for 5-hydroxyindoles was negative, these workers produced evidence that the oat-cell carcinoma in their patient was directly responsible for the endocrine secretion. We now report a third patient with oat-cell carcinoma and associated carcinoid syndrome: this report confirms and extends the original observations. In addition, the relation of oat-cell carcinoma to bronchial carcinoid is discussed.

\section{CASE REPORT}

A housewife aged 55 years complained of diarrhoea and occasional griping abdominal pain in December 1961. The diarrhoea was watery; no blood was noticed. She passed an average of three to six motions per day. In January 1962 her husband died suddenly and after this the diarrhoea became worse, amounting to 20 to 30 yellowish-brown motions per day. The severity of the diarrhoea fluctuated, and she continued to complain of generalized griping abdominal pain which sometimes woke her at night. Weakness and prostration were prominent symptoms. In March 1962 she noticed swelling of the legs, which apparently appeared abruptly since the patient noticed it on the day immediately before she was seen in the outpatient department.

In May 1961 she had had a 'nervous breakdown' attributed to business worries and complained of 'lacking zest'. This necessitated treatment with phenobarbitone. It is not clear whether the environmental factors were the major cause of her ill-health at this time or whether the symptoms were in any way related to the disease that became clinically overt seven months later. She had had a productive cough for some years, sufficient to earn her the label of 'chronic bronchitic'. She was a heavy smoker.

She was admitted to Edgware General Hospital on 19 March 1962 under the care of Dr. F. Allen Binks.

PHYSICAL EXamination She was an obese, anxious woman with a florid facial complexion and some tanning of the exposed skin. The flush was restricted to the face and neck and did not alter appreciably in intensity during her stay in hospital. No telangiectases were present. There was no clubbing of the fingers and no peripheral lymphadenopathy. There was pitting ankle oedema of moderate degree.

The pulse rate was 96 , regular. Blood pressure was $140 / 60 \mathrm{~mm}$. Hg. Heart sounds were normal. The liver was palpable $3 \mathrm{~cm}$. below the right costal margin in the mid-clavicular line extending across the epigastrium to below the left costal margin. Nonumbilicated nodules were felt on its surface. She had inflamed prolapsed piles. Rectal examination was difficult because of sphincter spasm but revealed no abnormality.

INVESTIGATIONS Haemoglobin was $13.2 \mathrm{~g} / / 100 \mathrm{ml}$., leucocytes $8,900 /$ c.mm. (neutrophils $60 \%$, lymphocytes $36 \%$, monocytes $4 \%$ ). Blood urea was $24 \mathrm{mg}$./ $100 \mathrm{ml}$., serum sodium $144 \mathrm{mEq} / \mathrm{l}$., potassium $3.6 \mathrm{mEq} / 1$., and chloride $103 \mathrm{mEq} / \mathrm{l}$. Serum protein was $5.5 \mathrm{~g} . / 100 \mathrm{ml}$. (albumin $3.0 \mathrm{~g} . / 100 \mathrm{ml}$.; globulin $2.5 \mathrm{~g} . / 100 \mathrm{ml}$.). The stools were watery and dark brown and contained no obvious mucus or blood. Bacteriological investigation of the stools showed no pathogenic organisms.

Examination of a 24-hour specimen of urine showed greatly increased excretion of 5-hydroxyindole-acetic acid (5-HIAA), but unfortunately no quantitative assay was carried out. Two-dimensional chromatography of the urine showed the 5-hydroxyindole excretion pattern characteristic of the classical variety of carcinoid syndrome with a large spot corresponding to 5-HIAA and small traces of 5-HTP and other indoles.

Chest radiographs showed broadening of the upper mediastinal shadow with projection mainly into the 


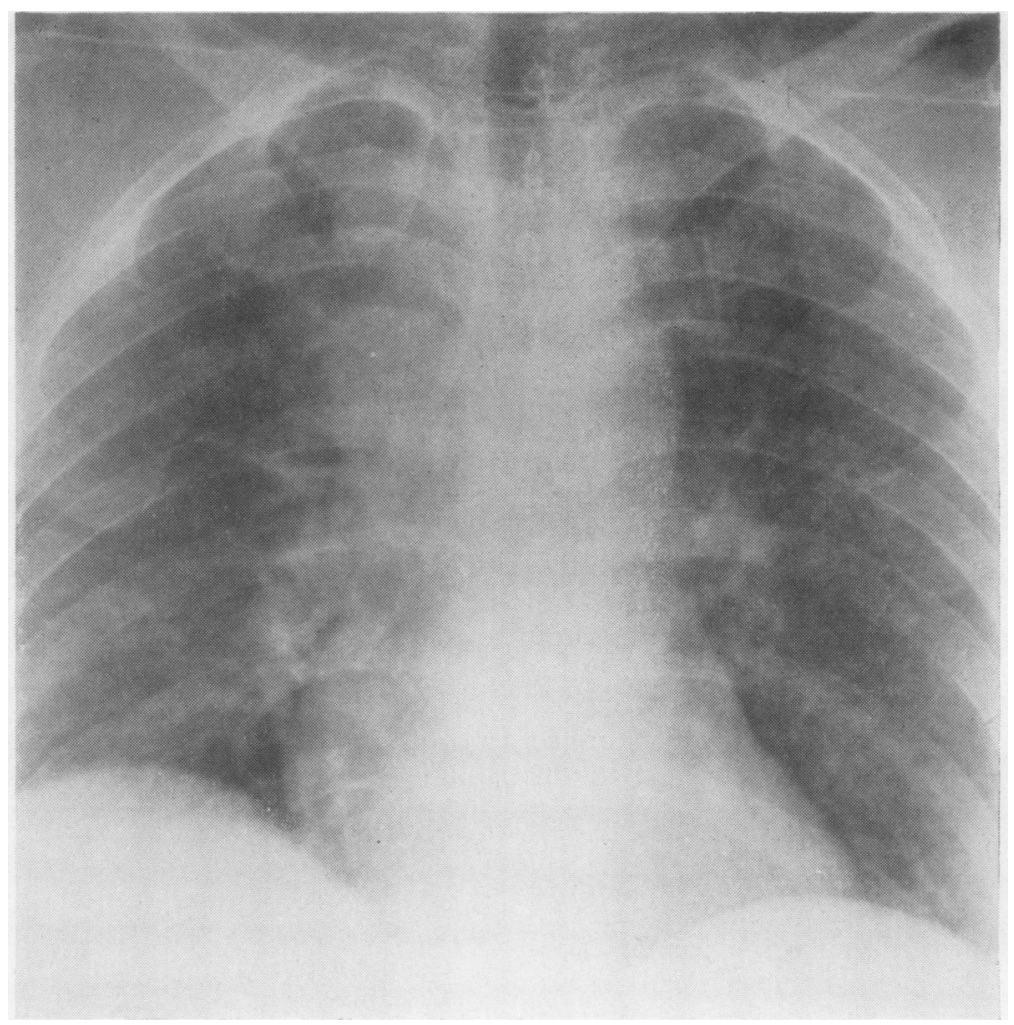

FIG. 1. Radiograph of the chest showing upper mediastinal mass.

right lung field (Fig. 1). A barium meal and followthrough and a barium enema showed no evidence of any abnormality in the alimentary tract.

COURSE Her general condition remained poor. The diarrhoea continued, but the frequency of the motions decreased. On 31 March 1962 she became pyrexial, the temperature rising to a peak of $101.2^{\circ} \mathrm{F}$. on 4 April 1962. Crepitations were heard over both lung fields, more marked on the right. She was treated with tetracycline, $250 \mathrm{mg}$. six-hourly for three days; as there was no apparent response to this therapy, she was given crystalline penicillin, 500,000 units intramuscularly b.d., with a drop in the temperature to normal after two days. There was no significant change in electrolytes except for the serum potassium, which dropped to $3.0 \mathrm{mEq} / 1$. on 6 April 1962, despite the fact that she was receiving $1 \mathrm{~g}$. $\mathrm{KCl}$ orally t.d.s. The liver was now grossly enlarged and nodular. There had been an obvious loss of weight since her admission to hospital. Marked lessening of ankle oedema was noted a few days before death. The previously florid complexion had become more dusky. She died on 13 April 1962.

NECROPSY The pleurae were normal. There was sparse but scattered nodular neoplastic infiltration in all the lung lobes, with nodules up to $0.5 \mathrm{~cm}$. in diameter. The site of origin of the bronchial carcinoma could not be determined. The hilar and tracheobronchial lymph nodes were extensively replaced by tumour, individual glands measuring up to $4 \mathrm{~cm}$.

The liver was greatly enlarged, weighing $4,720 \mathrm{~g}$. It was extensively replaced by tumour nodules up to $6 \mathrm{~cm}$. in diameter. The biliary tract was normal. There was extensive neoplastic infiltration of the pancreas. The whole of the alimentary tract was carefully examined and no tumour was found. A few calcified mesenteric lymph nodes were present.

The pericardium was normal. The heart $(380$ g.) had a normal myocardium. There was no sign of valvular or endocardial disease, though this was carefully sought. Moderate non-occlusive atheroma of the coronaries was present. The right adrenal contained metastatic tumour; the left showed gross hypertrophy without obvious metastasis.

The kidneys $(320 \mathrm{~g}$.) had smooth surfaces, easily strippable capsules, and a faint blurring of normal corticomedullary markings. Numerous tumour nodules, up to $3 \mathrm{~mm}$. in diameter, were present.

The brain $(1,200$ g.), spleen $(150$ g.), and other organs showed nothing significant. 
HISTOLOGY The tumour was a typical oat-cell carcinoma with streaming and ribboning of the ovoid, hyperchromatic cells (Azzopardi, 1959); rosette formation was very scanty. Numerous areas of necrosis were related to encrustation of blood vessels and fibrous stroma by deoxyribonucleic acid, a highly characteristic feature of oat-cell carcinoma and one not often seen in other malignant tumours (Fig. 2). The metastases in the liver, kidneys, pancreas, and other sites also had the structure of an oat-cell tumour. Metastases were identified microscopically in the thyroid and in both adrenals. The adrenals were hypertrophied, the cortical width increased, and the combs thickened independently of tumour infiltration. The zona fasciculata was largely converted to compact cells, occasionally interrupted by groups of grossly ballooned cells. The zona glomerulosa was reduced on average, its cells appearing compressed and distorted.

The only other pathological findings were small foci of fat necrosis around the pancreas and some

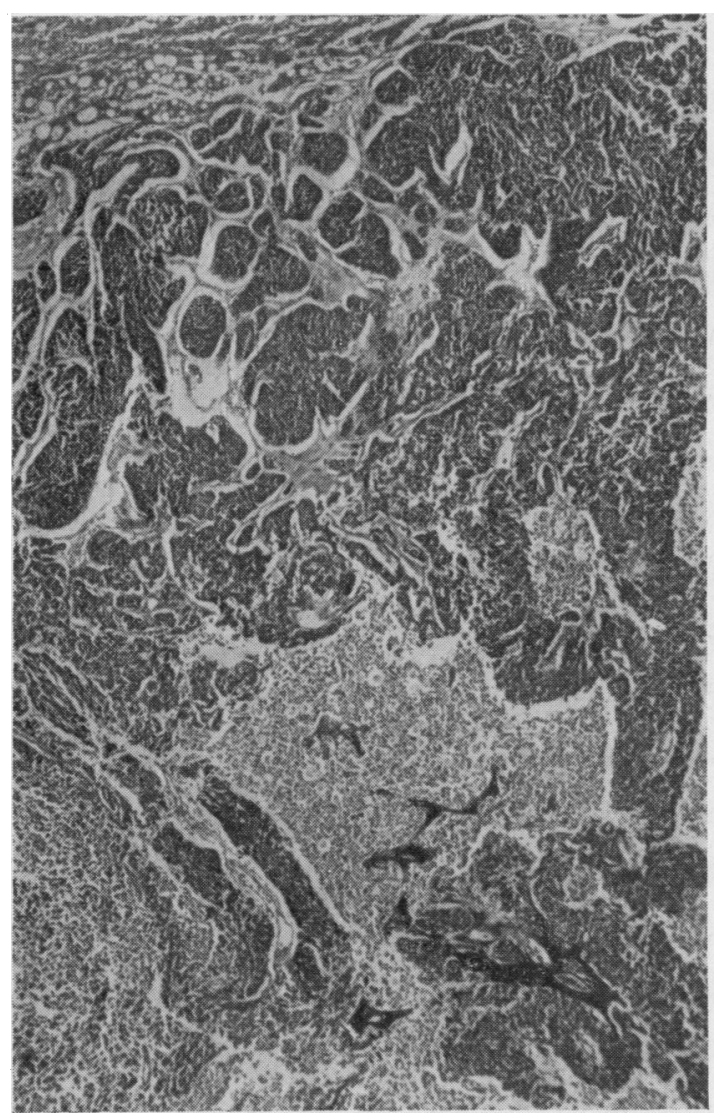

FIG. 2. Oat-cell carcinoma in liver. Deoxyribonucleic acid deposited on stroma appears black. Haemalum and eosin, $\times 45$. 'colloid nodules' in the thyroid separated by hyalinized areas.

ADDITIONAL INVESTIGATIONS No argentaffin or diazopositive cells were found in the tumour, as would be expected anyway in necropsy material. A few silverimpregnatable cells were, however, demonstrated by the Bodian technique. There was no definite autofluorescence. Macrophages in necrotic areas of the tumour contained argyrophilic cytoplasmic particles that fluoresced pale yellow in ultraviolet light and gave a positive Schmorl reaction; these particles could represent nuclear or cytoplasmic debris of tumour cells containing $5-\mathrm{HT}$ in sufficient concentration to give these reactions; this is not proved as the more specific alkaline diazo reaction was negative.

\section{DISCUSSION}

This patient is, to our knowledge, the third on record with an oat-cell bronchial carcinoma associated with the carcinoid syndrome. In all three patients no tumour was present in the alimentary tract, and careful examination showed no evidence of a carcinoid tumour anywhere in the body. The site of origin in the bronchial tree of an oat-cell carcinoma is occasionally very difficult to determine, as the primary tumour may be measured in millimetres in the presence of widespread metastatic disease. Where, as in the present patient, multiple nodules are found in the lungs, the site of origin may be impossible to determine. On the other hand, the specific identification of a tumour as an oat-cell carcinoma is possible, given adequate and well-processed tissue. This identity was established here, using criteria laid down elsewhere (Azzopardi, 1959). In our patient even the characteristic 'D.N.A. sheaths' were present, though the nature of the tumour could be established even in their absence. This is stressed because, as Gowenlock et al. (1964) rightly point out, the differentiation between oatcell carcinoma and a carcinoid, although usually easy, occasionally presents some difficulty even to a pathologist experienced in this field.

The adrenal hyperplasia was a striking and unexpected feature at necropsy. It will be recalled that the serum potassium had dropped to $3.0 \mathrm{mEq} / 1$. on 6 April in spite of oral potassium supplements, and at a time when the severity of the diarrhoea had decreased. It is tempting to think that this patient might have been developing hypokalaemic alkalosis, as is found sometimes with oat-cell tumours with or without the clinical features of Cushing's syndrome; the evidence is, however, only suggestive.

The lessening of leg oedema terminally calls for 
comment. Oedema unrelated to cardiac failure is a well-known feature of the carcinoid syndrome. It is recognized that carcinoid tumours may exhibit a sharp drop in the production of hydroxyindoles and other metabolites in the terminal stages of an illness. If oat-cell carcinoma behaves similarly, the lessening of the leg oedema may merely reflect diminished metabolic activity of the tumour. This patient was, however, given $75 \mathrm{mg}$. chlorpromazine daily, a dosage later increased to $100 \mathrm{mg}$., and the diminution of the oedema followed the initiation of this therapy. Sjoerdsma and Melmon (1964) point out that chlorpromazine and related drugs have anti-bradykinin properties, an action offering some basis for impressions of objective improvement with this therapy in patients with the carcinoid syndrome. It is possible that chlorpromazine contributed to the amelioration of oedema in this patient.

Of the three recorded patients with oat-cell bronchial carcinoma associated with the carcinoid syndrome, two have been studied in one medical school. This suggests that similar cases have been missed elsewhere. Numerous factors are responsible for this: not least of these is the fact that, until recently (Gowenlock et al., 1964), only a single authentic instance of this association had been recorded (Williams and Azzopardi, 1960). It is our hope that by drawing attention to this association more cases will be recognized. The overall incidence of the carcinoid syndrome in patients with oat-cell carcinoma must nonetheless be very low, taking into account the incidence of this variety of tumour. In some patients biochemical abnormalities may be present in the absence of overt clinical evidence. Gowenlock, Campbell, and Platt (1963) have produced evidence in support of this. Parish, Crawford, and Spencer (1964) discovered by chance a high level of 5-HT in the pulmonary venous drainage of an oat-cell carcinoma of the bronchus. In case 2 of Meador, Liddle, Island, Nicholson, Lucas, Nuckton, and Luetscher (1962) a 'small-cell' carcinoma of the bronchus in a man of 53 years, associated with the biochemical features of Cushing's syndrome, was associated also with a urinary 5-HIAA output of $50 \mathrm{mg} . / 24$ hours without symptoms of the carcinoid syndrome. This is analogous to the situation in some patients with a bronchial carcinoid (Warner, Kirschner, and Warner, 1961).

A number of cases of pancreatic or other carcinoma have been reported in association with the carcinoid syndrome. The reports of Arnett and Long (1931), Rosenbaum, Santer, and Claudon (1953), and McMullen and Hanson (1958) do not describe or illustrate the tumours and cannot be $\frac{}{5}$ accepted as authentic. Dengler (1959) describes a क 'simple medullary carcinoma of the pancreatic $\overparen{\Phi}$ tail' in which no 'silver-stainable' cells were present, but argentaffin cells are not essential to ${ }^{\infty}$ the diagnosis of carcinoid even in freshly fixed $\vec{\circ}$ material, and, secondly, argentaffin cells cannot be found unless tissue is fixed within a few hours of ${ }^{\omega}$ death. The 'pancreatic-duct neoplasm' reported $\rightleftharpoons$ by Peart, Porter, Robertson, Sandler, and Baldock (1963) is certainly not a conventionalo pancreatic adenocarcinoma and their equivocation or on this point is unfortunate. Carcinoids and oatcell carcinomata of the bronchus are the only

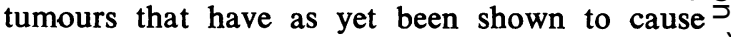
the carcinoid syndrome.

The 'classical' carcinoid syndrome is associated $\frac{\mathbb{D}}{8}$ with the production of 5-HT by the tumour. Since $\overrightarrow{\mathbb{D}}$ the pioneer work of Sandler and Snow (1958) it has become clear that there is a carcinoid tumour $\stackrel{\Phi}{-}$ variant which is a 5-HTP secretor and that this $\vec{\bullet}$ variant is more frequent in sites like the stomach, of pancreas or bronchus than in the small intestine (Williams and Sandler, 1963). On the other hand, of four primary bronchial tumours with the carcinoid syndrome studied in our department, three have been 5-HT secretors (Williams and Azzopardi, 1960 ; Clinicopathological Conference, 1963); the fourth, the subject of the present report, was probably also a 5-HT secretor, judging by the urinary chromatogram. This and other published data suggest that the 5-HT secretor is more common than the 5-HTP secretor even in bronchial neoplasms.

The histochemical resemblances between bronchial and intestinal carcinoids (Williams and Azzopardi, 1960) have been generally accepted, though oे the quantitative differences should be borne in $₹$ mind. Argyrophilia and autofluorescence (mainly 을 nuclear) of the bronchial carcinoids are among their common characteristics. In our previous oat- o cell tumour with the carcinoid syndrome, we found a weak and patchy nuclear fluorescence and of a high 5 -HT content of $20 \mu \mathrm{g}$./g. wet tumour $N$ tissue. Reasons were given for believing that the cytoplasmic storage mechanism for 5-HT in oat- 0 cell carcinoma was largely defective, accounting $\underset{<}{<}$ for some of the difficulties of demonstrating it histochemically: Gowenlock et al. (1964) have $\stackrel{\oplus}{\rightarrow}$ supported this argument. In the patient reported 0 here, we were fortunate in finding a few argyrophil cells in the oat-cell carcinoma, a unique find- $\mathbb{\mathbb { D }}$ ing, forging another link in the similarity of the $\bar{D}$ pattern of differentiation of the oat-cell tumour and the bronchial carcinoid. This is not to be 
interpreted as meaning that a tumour that starts as a bronchial carcinoid can undergo metamorphosis to an oat-cell carcinoma, for the clinicopathological evidence is so far overwhelmingly against this view.

It is at first sight remarkable that a tumour of the order of malignancy of oat-cell carcinoma can be associated with a syndrome seen more frequently with carcinoid tumours. It might be argued that better differentiated tumours are more likely to be associated with the production of pharmacologically active substances. This is true in certain tumours, e.g., of some endocrine glands : the reverse is true in certain other situations. Oatcell carcinomata have an immense generating potential and may produce an array of hormones (e.g., adrenocorticotropic hormone-, melanocyte stimulating hormone-, and antidiuretic hormonelike substances), 5-hydroxyindoles, etc. Because they do not always function efficiently as a storehouse, the demonstration of these substances in the tumour itself is sometimes difficult.

\section{SUMMARY}

The third instance of a patient with an oat-cell carcinoma associated with the carcinoid syndrome is reported: this was very probably a 5-HT secretor. Carcinoids and oat-cell carcinomata are the only tumours in which a causal relationship to the carcinoid syndrome has been established. Structural, biochemical, and cytochemical resemblances between the two tumours are pointed out. These resemblances are thought to represent rudimentary differentiation towards carcinoid tumours in a very small percentage of oat-cell carcinomata.

We wish to thank Dr. F. Allen Binks, under whose care this patient was admitted, and Miss E. W. M. Johnson and Dr. M. Carter for the biochemical investigations and necropsy report.

We are indebted to Professor C. V. Harrison for his valuable criticism, to Mr. E. Hamilton for technical assistance, and to Miss S. Lee for typing the manuscript. We wish to thank the B.E.C.C. for supplying technical aid.

\section{REFERENCES}

Arnett, J. H., and Long, C. F. (1931). A case of congenital stenosis of the pulmonary valve, with late onset of cyanosis: death from carcinoma of the pancreas. Amer. J. med. Sci., 182, 212.

Azzopardi, J. G. (1959). Oat-cell carcinoma of the bronchus. J. Path. Bact., 78, 513.

Clinicopathological Conference (1963). A complicated case of carcinoid disease. Brit. med. J., 1, 1397.

Dengler, H. (1959). Atypisches Carcinoidsyndrom mit vermehrter Ausscheidung von 5-Hydroxyindolessigsäure bei Pankreascarcinom. Klin. Wschr., 37, 1245.

Gowenlock, A. H., Platt, D. S., Campbell, A. C. P., and Wormsley, K. G. (1964). Oat-cell carcinoma of the bronchus secreting 5-hydroxytryptophan. Lancet, 1, 304.

- Campbell, A. C. P., and Platt, D. S. (1963). Biochemical interrelationships between bron hial adenomas and carcinomas. Proc. Ass. clin. Biochem., 2, 208.

Kinloch, J. D., Webb., J. N., Eccleston, D., and Zeitlin, J. (1965). Carcinoid syndrome associated with oat-cell carcinoma of bronchus. Brit. med. J., 1, 304.

McMullen, F. F., and Hanson, H. H. (1958). Excessive urinary 5-hydroxy-3-indole acetic acid in the absence of a metastatic carcinoid. Circulation, 18, 883.

Meador, C. K., Liddle, G. W., Island, D. P., Nicholson, W. E., Lucas, C. r., Nuckton, J. G., and Luetscher, J. A. (1962). Cause of Cushing's syndrome in patients with tumors arising from 'nonendocrine' tissue. J. clin. Endocr., 22, 693.

Parish, D. J., Crawford, N., and Spencer, A. T. (1964). The secretion of 5-hydroxytryptamine by a poorly-differentiated bronchia carcinoma. Thorax, 19, 62

Peart, W. S., Porter, K. A., Robertson, J. I. S., Sandler, M., and Baldock, E. (1963). Carcinoid syndrome due to pancreatic-duct neoplasm secreting 5-hydroxytryptophan and 5-hydroxytryptamine. Lancet, 1, 239.

Rosenbaum, F. F., Santer, D. G., and Claudon, D. B. (1953). Essential telangiectasia, pulmonic and tricuspid stenosis, and neoplastic liver disease. A possible new clinical syndrome. J. Lab. clin. Med., 42, 941 .

Sandler, M., and Snow, P. J. D. (1958). An atypical carcinoid tumour secreting 5-hydroxytryptophan. Lancet, $1,137$.

Sjoerdsma, A., and Melmon, K. L. (1964). The carcinoid spectrum. Gastroenterology, 47, 104.

Warner, R. R. P., Kirschner, P. A., and Warner, G. M. (1961). Serotonin production by bronchial adenomas without the carcinoid syndrome. J. Amer. med. Ass., 178, 1175.

Williams, E. D., and Azzopardi, J. G. (1960). Tumours of the lung and the carcinoid syndrome. Thorax, 15, 30.

and Sandler, M. (1963). The classification of carcinoid tumours. Lancet, 1, 238.

\section{ADDENDUM}

Since submission of the manuscript, Kinloch, Webb, Eccleston, and Zeitlin (1965) have reported another case of carcinoid syndrome with an oatcell carcinoma of the bronchus. This strengthens the evidence for a genuine association between the two disorders. 